\title{
An Analysis of Cohesion and Coherence of Descriptive Texts Written by Junior High School Students
}

\author{
Galis Muthia Zahra*, Emi Emilia, Iyen Nurlaelawati \\ English Language Study Program, Universitas Pendidikan Indonesia \\ *Corresponding author. Email: galismuthia@student.upi.edu
}

\begin{abstract}
The study aims to investigate the cohesion and coherence of descriptive texts written by seventh grade junior high school students. This study was conducted in the even semester of the 2019/2020 academic year during the Covid-19 pandemic. This study used a qualitative case study design, and the data were obtained from six texts representing high, middle, and low achiever students. To identify the texts' cohesion and coherence, the grammar of textual metafunction from systemic functional linguistics (SFL), that is the theme system was used. The findings show that all students had the ability to make descriptive texts in terms of cohesion and coherence. All texts successfully used different types of themes, including topical and textual themes, and thematic progression, including the zigzag and reiteration patterns to create coherence especially at the clause level. Various cohesive devices such as reference, conjunction, lexical, and ellipsis were also used to create a cohesive text. It was also found that the texts written by high achiever students were more coherent than the texts written by middle and low achiever students due to several aspects such as the more diverse pattern and the more frequent use of pattern. In addition, the high and middle achiever texts seemed more cohesive than the low achiever texts due to the high number of cohesive devices used in the middle achiever texts, and high number of conjunctions used in the middle and high achiever texts. Based on the findings, more support is needed from teachers when teaching descriptive text to middle and low achiever students, especially in a pandemic era.
\end{abstract}

Keywords: Cohesion, coherence, descriptive text, theme system, systemic functional linguistics

\section{INTRODUCTION}

The government in Indonesia is very concerned in developing students' writing ability because writing has a role in the success of students learning. This can be seen from the curriculum that emphasizes the development of students' writing ability. Based on the syllabus, when students begin to formally study English in school, they are required and expected to write different types of text. In the 2013 Curriculum, the curricula that applied in Indonesia, junior high school students are required to be able to write several genres, one of which is descriptive text. In the syllabus, it is stated that seventh grade junior high school students are expected to be able to write a descriptive text by paying attention to its social functions, generic structure, and linguistic features.

In writing, students are expected to be able to make a cohesive and coherent text (Krisnawati, 2013). A text is said to be cohesive if the sentences or clauses are connected to one another since cohesion indicates continuity between a discourse and another (Crossley,
Kyle, \& McNamara, 2016; Wang \& Guo, 2014). This can be achieved by applying "semantic ties" in the form of cohesive devices to make texts bond together to form a unified whole (Eggins, 2004; Halliday \& Hasan, 1976; Rahman, 2013). Meanwhile, coherence relates to context of situation and context of culture. Thus, a text is said to be coherent if the readers can recognize the situation occurring in the text, can identify the genre of the text, and can assume that the text makes sense (Eggins, 2004; Emilia, 2014; Halliday \& Hasan, 1976, 1989; Hyland, 2006).

However, creating cohesion and coherence in the text is not easy, and it becomes a problem for writers, especially the writers of English as a foreign language (Ahmed, 2010; Hammad, 2016; Hasan \& Marzuki, 2017; Rahman, 2013; Rahmatunisa, 2014). Cohesion and coherence become the problem because students do not show awareness on the relations of meaning between clauses and sentences in their texts. This happens due to the lack of explanation given by teachers and lack of writing practice. In addition, the time of instruction is 
also limited so that students have little space to create/write cohesive and coherent texts (Hammad, 2016; Hasan \& Marzuki, 2017).

In Indonesia, many studies have been conducted regarding cohesion and coherence of a text. One of the studies was conducted by Mardhatillah (2013) who focuses on analysing cohesion and coherence in the background section written by undergraduate students in Bandung. This study showed that several cohesive devices were used to create cohesion. However, from the analysis of the structure of the background, it was known that there were several aspects that influenced the cohesion and coherence of the text. First, some elements in the background did not occur in the text. The missing elements affected the cohesion and coherence of the text. Second, the lack of thematic patterns also affected coherence because the ideas conveyed were not connected.

Another study regarding cohesion was also conducted by Emilia, Habibi, and Bangga (2018). The study analysed exposition texts written by high school students representing low, middle, and high achiever students. The researchers examined generic structure, theme progression, and cohesive devices to find out whether the analysed texts were cohesive or not. The results of the study found that in terms of thematic progression, reiteration patterns and zigzag patterns were found in all texts, meanwhile multiple theme patterns were only found in the texts written by high achiever students. In addition, various cohesive devices were used to create cohesion in the text. Lexical cohesion was the most used cohesive device followed by conjunction, reference, and ellipsis.

In analyzing texts cohesion and coherence, the theme system in systemic functional linguistics (SFL) can be used. Nevertheless, the analysis of the theme system in the texts written by junior high school students has not been thoroughly researched. In addition, research that analyses students' descriptive texts at an early stage has not been widely carried out. Meanwhile, it is important to know students' abilities as well as students' difficulties in writing descriptive texts. Therefore, this study investigates the cohesion and coherence of descriptive texts written by seventh grade junior high school students using systemic functional linguistics approach, and cohesive devices theory proposed by Halliday and Hasan (1976).

\section{METHODS}

This study used a qualitative design since it was done in a school, a place where the problems under study occurred which was related to students' writing ability (Creswell \& Creswell, 2018; Merriam, 2009; Yin, 2011). In addition, since this study dealt with the analysis of documents in the form of students' texts, this study used a case study approach (Travem; Freebody in Emilia, 2005). The data taken from student's texts were then examined and interpreted to obtain meaning, knowledge and understanding of the topic being studied (Stake; Yin in Bowen, 2009). In this study, the documents studied and interpreted were seventh grade junior high school students' descriptive texts and focused on cohesion and coherence of the texts. This study examined six descriptive texts written by six seventh grade junior high school students from a junior high school in Bandung. The texts were written by students categorized as high, middle, and low achiever students. The analysed texts were collected from one class, and that was chosen because the class had the most submitted texts. In addition, the decision of students' proficiency level was recommended by the main teacher of the class.

To collect the data in this study, one research instrument was used. The instrument used was a document that contained descriptive texts. Two descriptive texts from each level of achievement were analysed in this study. The data were analysed in several stages. In the first stage, the sentences were divided into clauses. At this stage, because the texts being analysed were the first draft, there were still many grammatical errors. Therefore, the errors found in the texts were also corrected. In the second stage, the social purpose and the generic structure of the texts were investigated. In the next stage, the cohesive devices used in the text were examined. Finally, the texts were then analysed in terms of the theme system and theme progression based on the SFL approach.

\section{FINDINGS AND DISCUSSION}

To examine cohesion and coherence in descriptive texts, this study analysed social purpose and generic structure of the texts, cohesive devices, and theme system and theme progression.

\subsection{The Purpose and Generic Structure of the Students' Texts}

All texts analysed contained descriptions of people. Table 1 below shows the title of each descriptive text.

Based on Table 1, some of the texts use specific names of a person who comes from Indonesia and other countries. However, one of the texts does not show a

Table 1. The title of each text

\begin{tabular}{lll}
\hline \multicolumn{1}{c}{ Students } & Text & Titles \\
\hline High achiever & Text 1 & Kim Nam Joon \\
High achiever & Text 1 & Paul Pogba \\
Middle achiever & Text 1 & Vanesha Prescilla \\
Middle achiever & Text 1 & Naura \\
Low achiever & Text 1 & My Father \\
Low achiever & Text 1 & Iqbal Ramadhan \\
\hline
\end{tabular}


description of the specific name but it shows a description of the family, that is father. Therefore, in terms of the social purpose, all texts representing high, middle, and low achiever fulfil the purpose of descriptive texts because all texts contain description of a specific person (Gerot \& Wignell, 1994).

In addition, in terms of the generic structure, all texts have the structure stated by experts which are identification and description (Emilia \& Christie, 2013; Gerot \& Wignell, 1994). Below is an example of the structure in Text 1 , one of the descriptive texts analysed. In Figure 1, the identification section is indicated by introducing the person described. This part is stated in the first sentence. Furthermore, the second sentence to the last sentence is part of the description section that describes the physical characteristics, place of origin, and the achievements he has achieved.

However, the students seem to experience problems in classifying information. In the text, they write descriptions of physical appearance and personal judgments in the same paragraph. Whereas physical appearance and personal judgment should be written in different paragraphs. For instance, in Figure 1, there are descriptions of physical appearance and personal judgment in the description section stated in one paragraph as in "He is smart, tall, also has dimples, and has many talents". Whereas "smart" and "has many talents" are descriptions about mental judgment, and "tall" and "has dimples" are descriptions about physical appearance. Whereas each of these "must be written in different paragraphs" (Emilia, 2005).

When writing descriptive texts, students made several grammatical errors. These grammatical errors can confuse the reader in understanding the meaning conveyed through the text (Aunurrahman, Hamied, \& Emilia, 2017).

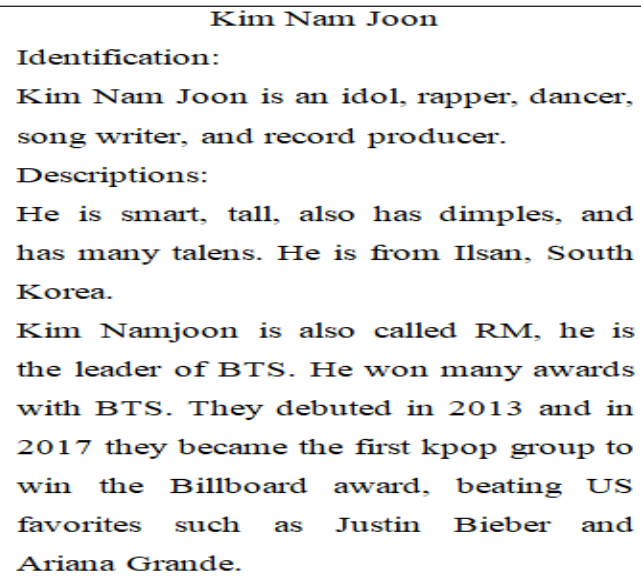

Figure 1 Generic structure analysis of Text 1.

These errors are in the form of subject verb agreement, inappropriate use of relative pronouns, incorrect use of pronouns, confusing sentence, missing article, misuse of pronoun, and mechanical errors such as in capital letters, and spelling. These errors are more frequently found in texts written by middle and low achiever students. In the interest of space, only some of the grammatical errors found in the texts are shown.

- (they) beating (beat) US favorites such as Justin Bieber and Ariana Grande (Text 1).

- $\quad h e(H e)$ is so jenius (genius) in football (Text 2).

- $\quad$ he can dribbling (dribble) the ball so well

- $\quad$ and she (is) a beautiful person (Text 3).

- Why do I like it (her)? (Text 4).

- $\quad H e($ She) has 4 Dongeng concerts (Text 4)

- He works consistentis (consistently) (Text 5).

- He has worked for almost 9 year (years) (Text 5).

- It (He) works consistently and responsibly (Text 5)

- he (He) likes Mie titi (mie titi) and Coto Makassar (coto makassar) (Text 6).

- $\quad$ he is the second cildren (child) of his parents (Text 6).

In addition, students from all levels of achievement also seem to have difficulty writing their ideas in the identification section. This is evidenced by the lack of information in the identification section as the identification section of all texts is not more than three sentences long.

\subsection{The Cohesive Devices Consistency}

In an attempt to create cohesive texts, various cohesive devices were used. Table 2 shows the various cohesive devices used in the texts. In Table 2, the cohesive devices used in the analyzed texts are reference, ellipsis, lexical, and conjunction. Reference device in the form of pronouns becomes the dominant cohesive device in the text. This finding is similar to Rahman (2013) who found pronouns as the most used cohesive device in descriptive texts. All references used refer to a person discussed in the text, and are taken from anaphoric reference. Therefore, the readers have to look back at the previous sentence/clause to find the identity of the participant since the referent is mentioned at the beginning of the text (Eggins, 2004). This can be seen in "Kim Nam Joon is an idol, rapper, dancer, song writer, and a record producer. He is smart, tall, ... (Text 1$) "$. To find out who is meant by "he" in the second clause, the readers have to look back at the first clause. 
Table 2. Cohesive devices used in all texts

\begin{tabular}{|c|c|c|c|c|c|c|}
\hline \multirow[t]{2}{*}{ Text } & \multicolumn{5}{|c|}{ Cohesive devices } & \multirow[t]{2}{*}{ Total } \\
\hline & Reference & Ellipsis & Substitution & Lexical & Conjunction & \\
\hline Text 1 & 7 & 1 & - & - & 3 & 11 \\
\hline Text 2 & 11 & - & - & 4 & 5 & 20 \\
\hline Text 3 & 14 & - & - & 6 & 7 & 27 \\
\hline Text 4 & 17 & 1 & - & 4 & 7 & 29 \\
\hline Text 5 & 11 & - & - & 5 & 2 & 20 \\
\hline Text 6 & 11 & - & - & - & 3 & 14 \\
\hline
\end{tabular}

Table 3. Conjunctions used in all texts

\begin{tabular}{ccccc}
\hline Text & \multicolumn{3}{c}{ Conjunction } \\
\cline { 2 - 5 } & Temporal Additive & Causal-conditional & Comparative & Comparative \\
\hline Text 1 & - & - & Also & And \\
Text 2 & - & - & - & And, but \\
Text 3 & When & - & - & And, not only. but also \\
Text 4 & - & Although & And, also \\
Text 5 & - & So, because & And \\
Text 6 & - & - & - & And \\
\hline
\end{tabular}

After reference, conjunction is another most widely used cohesive device. The texts that represent high and middle achievers use a more diverse conjunction than low achiever texts that only use one kind of conjunction. In addition, in terms of the number of conjunctions used, the texts representing the middle achiever use the most conjunctions compared to other texts. The types of conjunction such as temporal additive, causal conditional, comparative, and additive are found in all texts. Of all these conjunctions, the conjunction that is most widely used and is present in all texts is additive conjunction such as "and, but, not only, but also". This means that the conjunction is used by students when they want to add information and want to connect it to the previous sentence or clause (Habibi, 2014).

\subsection{The Theme Selection Consistency}

All texts written by low, middle, and high achievers use topical and textual themes. The topical theme in the form of unmarked topical theme is the most dominant theme in all texts.

The texts mostly use topical themes. The topical theme is used 60 times and 55 of them are unmarked topical themes. This supports the findings of previous studies conducted by Noprianto (2017); Potradinata (2018) who found that in descriptive texts, unmarked topical themes were the most frequently used theme. Unmarked themes are dominant because for students who are beginners in writing English, the easiest way to compose grammatically correct English sentences is to place pronouns or nominal groups as the subject of the sentence (Halliday in Arunsirot, 2013). In addition, the use of unmarked themes shows that students from all levels of achievements realize that in descriptive text, they must focus on a specific person which is realized by unmarked topical theme (Sianipar, 2015).

Another theme found in this study is the textual theme which is used 18 times. This type of theme is realized in coordinating conjunction (and, but), temporal conjunction (when), and subordinating conjunction (although). By using conjunctions as a textual theme, clauses will relate to one another so as to create a cohesive and coherent text (Arunsirot, 2013; Emilia et al., 2018). The theme in this study is also found in the form of a longer unit theme. There is a nominal group, as in "The dancer group is called "Dnau (Text 3)" and an embedded WH-clause as in "When I met him in France in 2016 he smiled to (at) me (Text 2)" which forms the theme. Only two of the longer unit themes were found in this study because the texts were written by students who are beginners in learning English, and they may not be able to write more complex sentences.

Unfortunately, in all texts there are no-higher level themes found. This type of theme is not found in the text making the text develop only locally. It also makes readers unable to predict what the text will be about. The absence of a higher theme may be because students do not realize the importance of a higher level theme that can signal and determine the type of text so that it leads to coherence (Emilia, 2005). 
Table 4. Theme found in all texts

\begin{tabular}{ccc}
\hline Text & Topical Theme & Textual Theme \\
\hline Text 1 & 9 & 1 \\
Text 2 & 10 & 3 \\
Text 3 & 14 & 4 \\
Text 4 & 12 & 7 \\
Text 5 & 8 & 1 \\
Text 6 & 15 & 2 \\
Total & 60 & 18 \\
\hline
\end{tabular}

Table 5. Theme patterns

\begin{tabular}{cccc}
\hline Text & Paragraph & \multicolumn{2}{c}{ Thematic Progression } \\
\cline { 3 - 4 } & & Reiteration & Zigzag \\
\hline Text 1 & 1 & $\checkmark$ & - \\
& 2 & $\checkmark$ & $\checkmark$ \\
Text 2 & 1 & $\checkmark$ & - \\
Text 3 & 1 & $\checkmark$ & - \\
& 2 & - & - \\
Text 4 & 1 & $\checkmark$ & - \\
& 2 & $\checkmark$ & - \\
Text 5 & 1 & $\checkmark$ & $\checkmark$ \\
& 2 & $\checkmark$ & \\
Text 6 & 1 & &
\end{tabular}

The absence of higher-level themes, and group or phrase complexes and embedded non-finite clauses as longer unit themes indicates that although several texts use various themes as shown in Table 4, the texts analyzed in this study are still rudimentary.

\subsection{The Thematic Progression Consistency of the Students Texts}

There are two types of theme pattern found in the texts, which are reiteration pattern and zigzag pattern. Table 5 shows the distribution of patterns in each text. The most frequently used pattern in this study is the reiteration pattern. This is similar to the findings of research conducted by Rakhman (2013). The use of this pattern shows that the text has a clear focus on the person being described because the same element is repeated in some clauses (Eggins, 2004). Therefore, the use of this pattern will make readers easier to track the participants discussed in the text, thereby creating coherence (Eggins, 2004; Emilia, 2014). Besides, this pattern also indicates that the students are trying to emphasize ideas by repeating them or it could be because the students lack vocabulary, so that the same word is repeated several times in the text (Bahaziq, 2016; Dastjerdi \& Samian, 2011).

Besides the reiteration pattern, some texts also have another pattern that is the zigzag pattern. This pattern is used as an effort to make the clauses in the text connected. The use of the zigzag pattern indicates that the clauses in those texts are connected to each other because the theme which is the topic of the clause has been introduced in the form of rheme in the previous clause (Emilia, 2010). The use of this pattern leads to coherence because it develops newly introduced information that will not be found in other patterns (Eggins, 2004; Emilia, 2014).

There are differences in the use of patterns between high, middle, and low achiever texts. In high achiever texts, almost all of the clauses have a pattern. This shows that the high achiever texts are more connected than middle and low achiever texts which can be seen in Figure 2 and Figure 3. In addition, the low and middle achiever texts are less varied in using patterns because there are texts that only have the reiteration pattern, namely Text 3 that can be seen in Figure 4, and Text 5 that can be seen in Figure 5.

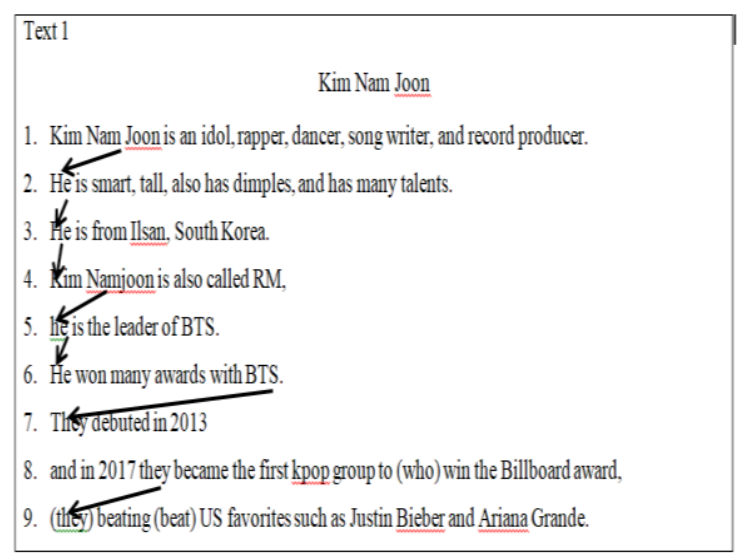

Figure 2 Text 1 written by a high achiever student.

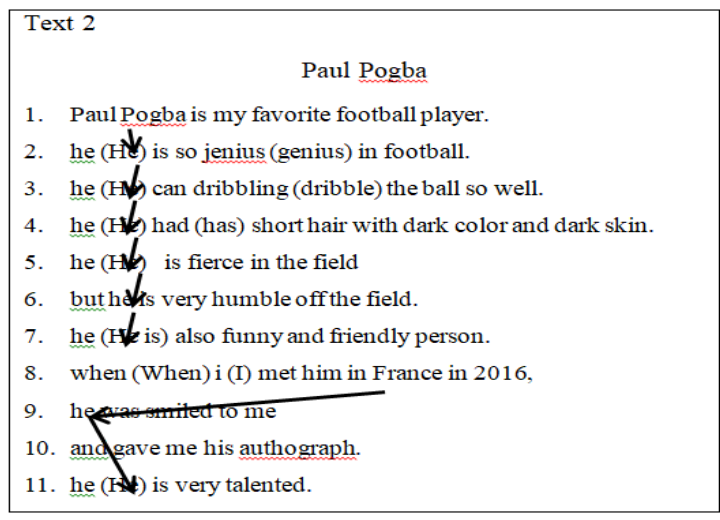

Figure 3 Text 2 written by a high achiever student. 


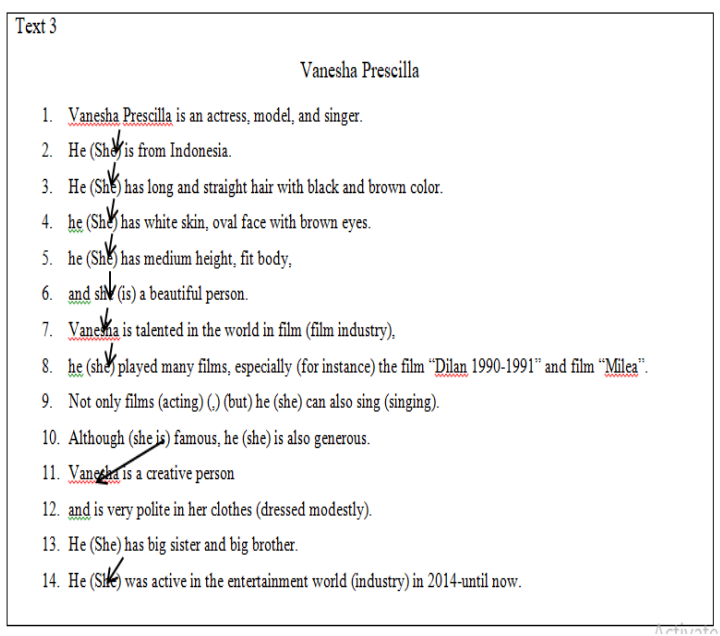

Figure 4 Text 3 written by a middle achiever student.

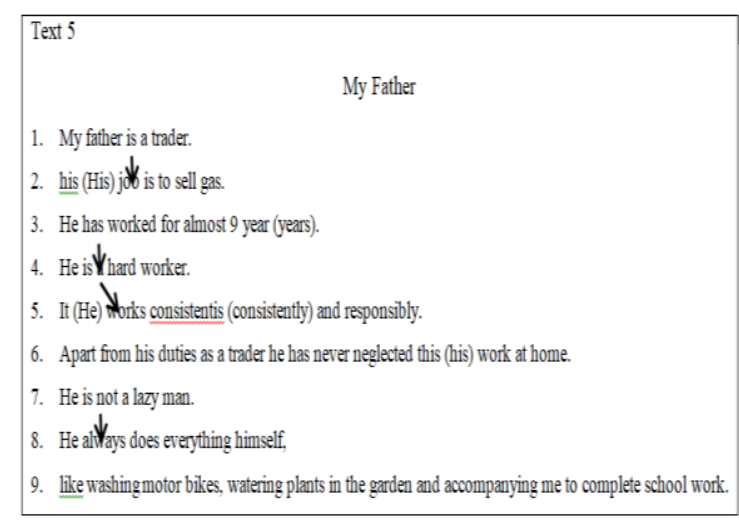

Figure 5 Text 5 written by a low achiever student.

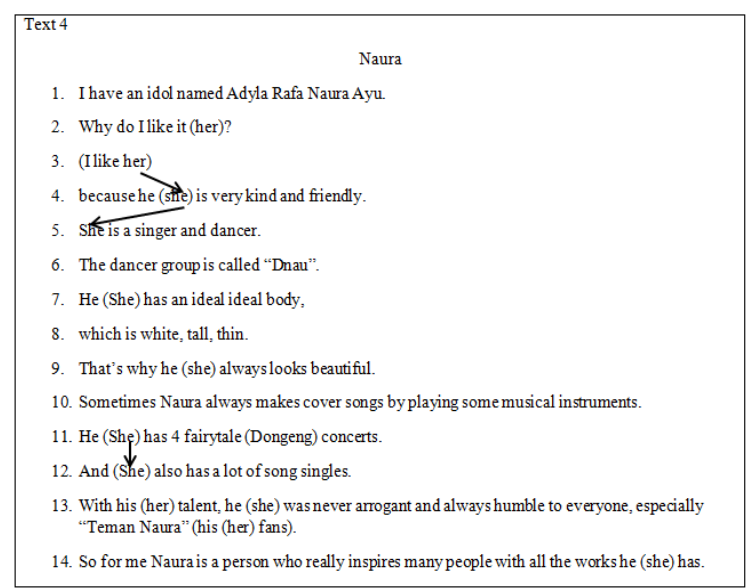

Figure 6 Text 4 written by a middle achiever student.

Apart from having only one type of pattern, the middle achiever text, Text 3 which can be seen in Figure 4 , also uses the reiteration pattern too often. In that text, there are ten reiteration patterns and no other patterns such as zigzag or multiple patterns are used. The overuse of the reiteration pattern is also found in study conducted by Arunsirot (2013) and Wang (2007). This excessive use of pattern may occur because for students, the only way to make clauses in the text connected is by repetition. Therefore, in order not to overly repeat the same pattern, the students are suggested to use other patterns such as the zigzag pattern or multiple theme patterns (Emilia in Mardhatillah, 2013). Other middle achiever texts, which are Text 4 (in Figure 6), Text 5 (in Figure 5), and Text 6 (in Figure 7), lack a pattern. The lack of patterns in the texts might be because the students, as beginner English learners and writers, do not have a clue how to make the information in a clause connect to other clauses. The lack of theme progression in a text makes it less developed and disconnected (Rahmawati \& Kurniawan, 2015).

\section{CONCLUSION}

The results of the analysis of generic structure, theme selection, theme progression, and cohesive devices showed that all texts showed great effort at creating cohesive and coherent texts. However, there are some similarities and differences regarding the results of the study between high, middle, and low achieving texts.

From the result of social purpose and generic structure, all texts written by high, middle, and low achievers could be categorized as descriptive text since all of the texts specifically described a person and had appropriate structures of a descriptive text. In terms of theme selection, there was no significant difference between the three levels of achievement. All of the texts used two themes, namely topical and textual themes. Topical themes in the form of the unmarked topical theme were used frequently in all texts. This result supported previous studies conducted by Noprianto (2017) and Potradinata (2018) who also found that unmarked topical theme was the dominant theme in descriptive texts. Regarding the theme progressions, reiteration pattern was a pattern that was used in all texts. This means all students tried to create coherence by repeating the same elements.

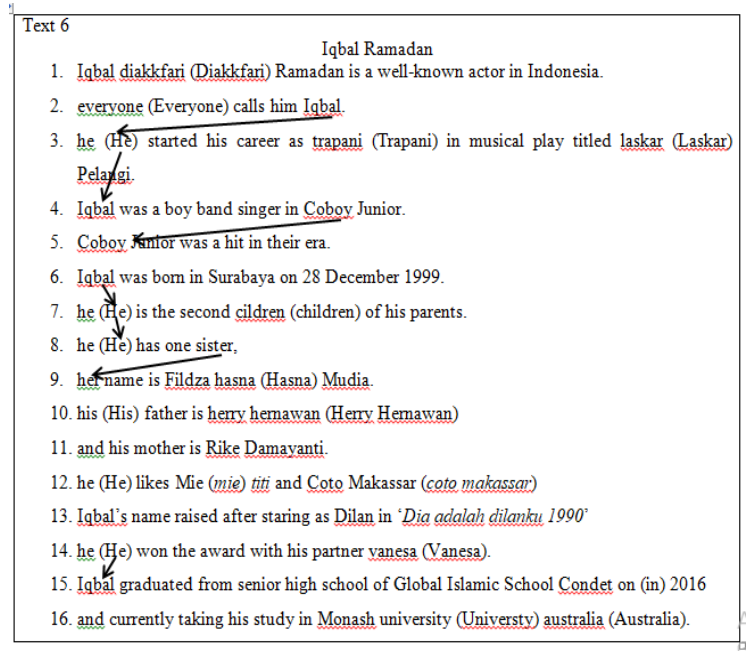

Figure 7 Text 1 written by a low achiever student. 
This pattern will make the readers easier to understand the focus of the text (Eggins, 2004; Emilia, 2014). However, high achiever texts were more coherent than middle and low achiever texts since high achiever texts used various patterns which almost occurred in every clause. Meanwhile the low and middle achiever texts were less varied in using theme patterns which resulted in repeating patterns, and lacking patterns. In an attempt to create a cohesive text, the students used various cohesive devices such as reference, conjunction, lexical, and ellipsis. Nevertheless, the high and middle achiever texts seemed to be more cohesive than the other texts. Those texts were more cohesive because the middle achiever texts used more variety of cohesive devices, and the middle and high achievers' texts used greater numbers of conjunctions. Even though all students showed good efforts in creating a cohesive and coherent text, teacher's guidance was still needed in terms of grammar, classifying information, and using the effective theme pattern so there will be no more excessive repetition or lacking a pattern in the text. Besides, excessive teaching regarding pronouns was also needed specially to middle and low achiever students since there were still some mistakes in using pronouns.

\section{REFERENCES}

Ahmed, A. H. (2010). Students' problems with cohesion and coherence in EFL essay writing in Egypt: Different perspectives. Literacy Information and Computer Education Journal (LICEJ), 1(4), 211221.

Arunsirot, S. (2013). An analysis of textual merafunction in Thai EFL student's writing. Novitas-ROYAL (Research on Youth and Language), 7(2), 160-174.

Aunurrahman, A., Hamied, F. A. H., \& Emilia, E. (2017). Exploring the tertiary EFL students' academic writing competencies. Indonesian Journal of Applied Linguistics, 7(1), 72-79.

Bahaziq, A. (2016). Cohesive devices in written discourse: a discourse analysis of a student's essay writing. English Language Teaching, 9(7), 112119.

Bowen, G. A. (2009). Document analysis as a qualitative research method. Qualitative Research Journal, 9(2), 27-40.

Creswell, J. W., \& Creswell, J. D. (2018). Research design: qualitative, quantitative and mixed methods approaches (5th ed.). Los Angeles: SAGE.

Crossley, S. A., Kyle, K., \& McNamara, D. S. (2016). The development and use of cohesive devices in L2 writing and their relations to judgments of essay quality. Journal of Second Language Writing, 32, 116.
Dastjerdi, H. V., \& Samian, S. H. (2011). Quality of Iranian EFL learners' argumentative essays: cohesive devices in focus. Mediterranean Journal of Social Sciences, 2(2), 65-76.

Eggins, S. (2004). An introduction to systemic functional linguistics (2nd ed.). London; New York: Continuum.

Emilia, E. (2005). A critical genre-based approach to teaching academic writing in a tertiary Efl context in Indonesia. [Unpublished doctoral's dissertation]. University of Melbourne.

Emilia, E. (2010). Teaching writing: Developing critical learners. Bandung, Indonesia: Rizqi Press.

Emilia, E. (2014). Introducing functional grammar. Bandung: Pustaka Jaya.

Emilia, E., \& Christie, F. (2013). Factual genres in english: learning to write, read, and talk about factual information. Bandung: Rizqi Press.

Emilia, E., Habibi, N., \& Bangga, L. A. (2018). An anlysis of cohesion of exposition texts: An Indonesian context. Indonesian Journal of Applied Linguistics, 7(3), 515-523.

Gerot, L., \& Wignell, P. (1994). Making Sense of Functional Grammar. Sydney: Gerd Stabler.

Habibi, N. (2014). An analysis of cohesion of students' exposition texts (a case study of a state senior high school in Bandung). [Undergraduate's thesis]. Universitas Pendidikan Indonesia, Bandung, Indonesia.

Halliday, M. A. K., \& Hasan, R. (1976). Cohesion in english. London: Longman.

Halliday, M. A. K., \& Hasan, R. (1989). Language, context, and text: aspects of language in a socialsemiotic perspective. Oxford: Oxford University Press.

Hammad, E. A. (2016). Palestinian university students' problems with EFL essay writing in an instructional setting. In Teaching EFL writing in the 21st century Arab world (pp. 99-124). Palgrave Macmillan, London.

Hasan, J., \& Marzuki, M. (2017). An analysis of student's ability in writing at Riau University Pekanbaru Indonesia. Theory and Practice in Language Studies, 7(5), 380-388.

Hyland, K. (2006). Teaching and research writing. In D. Airey, \& J. Tribe (Eds.), An International Handbook of Tourism Education. Pearson Education Limited.

Krisnawati, E. (2013). Applying Theme and Rheme in Indonesian EFL Students ${ }^{\text {ee }}$ Writing: An Attempt to 
Improve Cohesion and Coherence. International Journal of Language Learning and Applied Linguistics World, 2(2), 134-144.

Mardhatillah, W. (2013). Coherence and cohesion in the background section of the theses written by undergraduate students of english education program at one state university in Bandung (Research paper). [Master's thesis]. Universitas Pendidikan Indonesia, Bandung, Indonesia.

Merriam, S. B. (2009). Qualitative research: a guide to design and implementation. John Wiley \& Sons.

Noprianto, E. (2017). Student's Descriptive text writing in SFL perspectives. IJELTAL (Indonesian Journal of English Language Teaching and Applied Linguistics), 2(1), 65-81.

Potradinata, S. L. A. (2018). An analysis of student's descriptive text writing in systemic functional linguistic (SFL) perspectives. International Journal of Languages, Literature and Linguistics, 4(2), 121135.

Rahman, Z. A. A. A. (2013). The use of cohesive devices in descriptive writing by Omani student-teachers. SAGE Open, 3(4), 1-10.

Rahmatunisa, W. (2014). Problems faced by Indonesian EFL learners. English Review: Journal of English Education, 3(1), 41-49.

Rahmawati, R. V., \& Kurniawan, E. (2015). Thematic progression analysis in Indonesian EFL students thesis abstracts. Indonesian EFL Journal, 1(1), 8996.

Rakhman, A. N. (2013). An analysis of thematic progression in high school students' exposition texts. Passage, 1(1), 65-74.

Sianipar, R. T. (2015). Theme and thematic progression analysis of analytical exposition texts (Research paper). [Master's thesis]. Universitas Pendidikan Indonesia, Bandung, Indonesia.

Wang, L. (2007). Theme and rheme in the thematic organization of text: Implications for teaching academic writing. Asian EFL Journal, 9(1), 164176.

Wang, Y., \& Guo, M. (2014). A short analysis of discourse coherence. Journal of Language Teaching and Research, 5(2), 460-465.

Yin, R. K. (2011). Qualitative research from start to finish. New York: The Guilford Press. 